\title{
Bank Vault Security System
}

\author{
Ms Kumari $S^{1}$, Rathna Priyadarsini $S^{2}$, Reshma Chowdary $M^{3}$, Sahaana $K^{4}$, Vasantha @ Sindhuja $S^{5}$ \\ Department of Information Technology, Panimalar Engineering College, Chennai, Tamil Nadu, India ${ }^{1-5}$
}

\begin{abstract}
It is an understatement if we say that bank vaults are insecure. We place our trust in banks to contain our savings, both monetary and commodity. We often skim through the news of bank robberies in daily newspapers. The first treasuries were established within temples to ensure that they were protected not only physically, but also morally by the overseeing deity. Bank strong rooms evolved to incorporate increasing levels of physical security. Safes became vaults, with more steel and concrete being used. Similarly, lock technology increased in sophistication and complexity from simple keys to code combination. And bank heists began to find success via brute force - drilling, explosives etc. The proposed project aims to overcome the shortcomings (as in security) of the current vault systems provided in private banks. Here we use advanced methodologies like RFID, Face and Iris recognition system in an approach to automate the accessing of bank vaults. In order to protect the vaults from robbery a proximity sensor is being used here. GSM technology is also used to alert the account holders, the bank officials and the police force incase of an emergency. We intend to automate the manual security mechanism present at the moment so as to improve security levels and strength of the mechanism.
\end{abstract}

Keywords: Arduino uno, Biometric system, Servo motor, Relay

\section{I .INTRODUCTION}

\section{A. Need}

We live in a world where money is the most powerful tool which operates the machines called humans. Day by day the need for money keeps increasing. This crave for money is leading to an unhealthy society. Due to the economic increase the crime rate has increased to a greater extent. Especially robberies in banks has been a major threat in the society. This is due to the poor security system in the banks. And banks are in need of a security system which is advanced and cost efficient. Our main aim is to increase the efficiency of the security systems and provide atmost security to the bank vaults using advance methodologies. This ideology will be of a great use to the society in terms of easier access and trustable security of the bank vaults. This will stand as an evolution in upcoming bank security systems.

\section{B. Objective}

The sole objective of the project is to give complete protection and an advanced automation of accessing bank vaults. This ideology decreases the effort of the man power in safeguarding the bank vaults.

\section{Scope}

The main scope of the project is that it gives rapid enhancement in the banking field. It is a major outburst for providing advanced security to the bank vaults and for the efficient access of the bank lockers. It stands as an eyeopener for every business environment which lacks security.

\section{SYSTEM ANALYSIS}

\section{A. Existing system}

The existing system protects vaults through simple lock and keys. Each locker consists of two keys, one key is the master key which is with the bank manager the other one is with the customer. And the vault room key will be with the bank manager and a spare key will be left with the cashier. Every time a customer has to manually sign a record before entering the vault room for accessing his vault. Certain but limited private banks have evolved to use code combinations or fingerprint.

\section{B. Disadvantages Of Existing System}

The present system is less efficient in many ways. The records of the customers accessing the vaults maybe lost or ruined by some external source. Similarly a customer's fingerprint can be easily forged. The existing system can also allow the intruders to break in easily due to it's pure security mechanism.

\section{Proposed System}

The ideology of the project is to provide security and an easier way to access bank vaults. The proposed system provides access only to a limited set of people. It allows a bank employee, a cleaner and four authorized members per account (including the account holder). Two Security Mechanisms are provided here .At the first checkpoint, here the 


\section{International Journal of Advanced Research in Computer and Communication Engineering}

Vol. 8, Issue 2, February 2019

bank vault room's entrance, we place a two step security.

$\begin{array}{ll}\checkmark & \text { A Code Combination (PIN) } \\ \checkmark & \text { Face \& IRIS recognition }\end{array}$

During the RFID mechanism every authorized member, will be provided with a card. On inserting the card and providing the correct PIN, it proceeds to the next level. The next step of the process requires, every authorized member to successfully complete a face recognition in order to open that vault room and one half of the designated locker. At a time only two of the four authorized members may access the vault .A maximum of one attempt is accepted, on failure of which, an alert notification being sent to the account holder. The next step of authentication is the iris recognition. In order to open the remaining half of the locker, we place the iris scanner across the vault room. A maximum of 2 attempts are accepted, on failure of which, an alert notification being sent to the bank manager. The last and the important part of the project is to prevent the intruders. The proposed system will place a proximity sensor, right before the vaults. On any disturbance caused, the alarm will go off along with a notification being sent to the nearby police station.

\section{Advantages Of Proposed System}

Manual records need not be maintained hence chances of damage is less and man power is also reduced. And chances of forgery is also less compared to the previous systems. It becomes extremely difficult for the intruders to break in the vaults.

\section{E. Hardware Requirements \\ - Dc motor \\ - Servo motor \\ - Relay \\ - RFID sensor \\ - GSM board \\ - Ardino board \\ - Proximity sensor}

\section{F. Software Requirements}

- Operating system:windows 10

- $\quad$ Coading language:java

- $\quad$ Front end:jsp

- $\quad$ Back end:mysql

\section{SYSTEM DESIGN}

\section{A. System Architecture}

A system architecture or systems architecture is the conceptual model that defines the structure, behavior, and more views of a system. An architecture description is a formal description and representation of a system, organized in a way that supports reasoning about the structures and behaviors of the system.

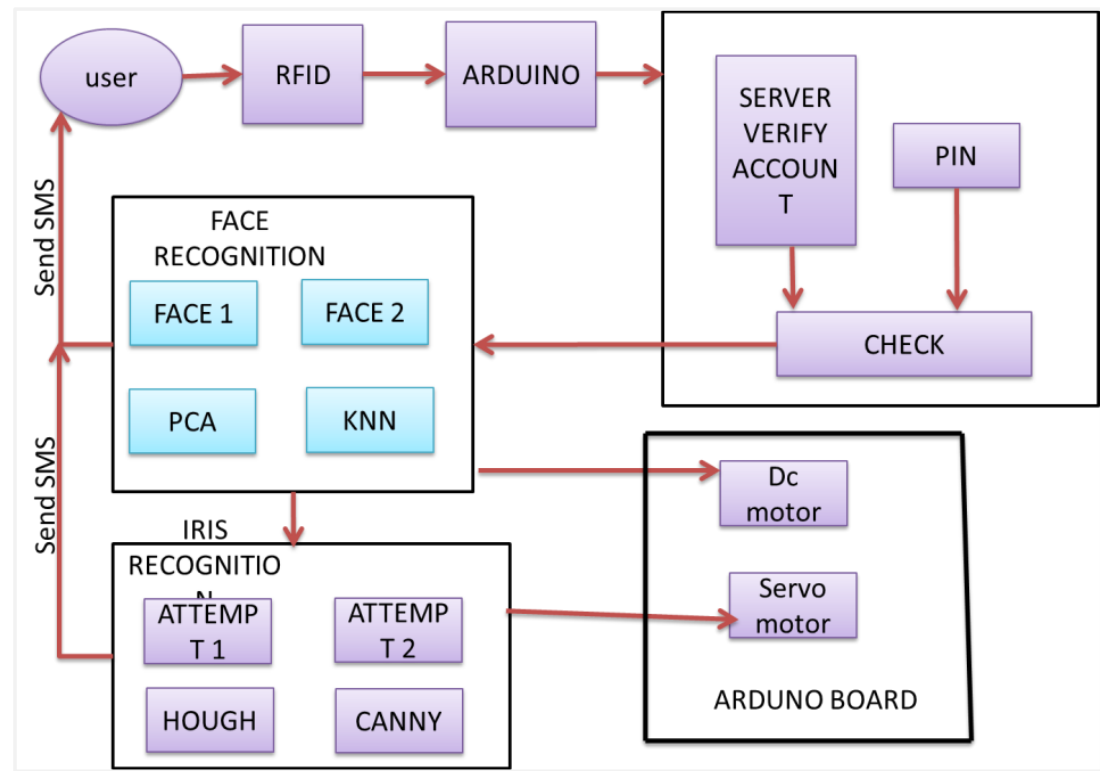

Fig. 1 System Architecture 
Vol. 8, Issue 2, February 2019

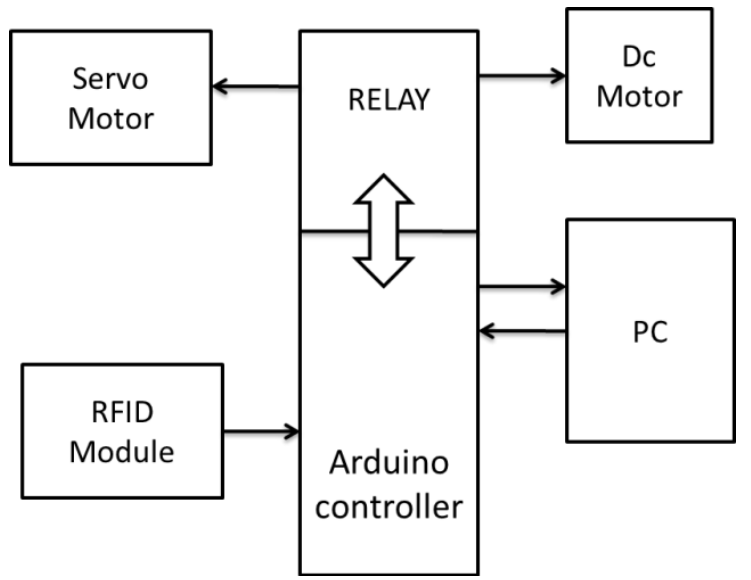

Fig. 2 IOT Architecture

\section{SYSTEM IMPLEMENTATION}

\section{A. PCA(Principle Component Analysis )}

Step 1: Prepare the data

Step 2: Subtract the mean

Step 3: Calculate the covariance matrix

Step 4: Calculate the eigenvectors and eigenvalues of the covariance matrix

Step 5: Select the principal components

Formulae:

$$
\begin{gathered}
A x=\lambda x \\
\text { covariance }(X, Y)=\frac{\sum_{i=1}^{n}\left(\overline{X_{i}}-X\right)\left(Y_{i}-y\right)}{(n-1)}
\end{gathered}
$$

\section{B. K NEAREST NEIGHBORS}

$\mathrm{K}$ nearest neighbors is a simple algorithm that stores all available cases and classifies new cases based on a similarity measure (e.g., distance functions). KNN has been used in statistical estimation and pattern recognition

$$
D=\sqrt{\left(x_{1}-y_{1}\right)^{2}+\left(x_{2}-y_{2}\right)^{2}}
$$

\section{C.CANNY EDGE DETECTION}

The pre-processing stage requires the localization of the iris which generally involves the detection of the edge of the iris as well as that of the pupil . Since varying levels of illumination can result in dimensional inconsistencies between eye images due to the stretching of the iris, normalization needs to be performed so that iris region is transformed to have fixed dimensions. Hough Transform is used for comparison of the iris image

\section{Method:}

1.Iris Localization

iris region approximated by a ring defined by the iris/sclera (limbic) boundary and the iris/pupil (pupillary) boundary, needs isolation by the removal of the Eyelids and eyelashes

2. Dimension Reduction and Iris Extraction

For the reduction of the computational complexity, the iris images are first converted into gray scale images. Next stage is the removal of unwanted information, such as eyelashes and eyelids which can be done using Sobel operator for detecting the edges Boundary Detection

Canny edge Detection:

$$
D=\sqrt{D_{x}^{2}(x, y)+D_{y}^{2}(x, y)}
$$


Vol. 8, Issue 2, February 2019

\section{SERVO MOTOR}

A servomotor is a rotary actuator or linear actuator that allows for precise control of angular or linear position, velocity and acceleration. It consists of a suitable motor coupled to a sensor for position feedback.

\section{E. RELAY}

A relay is a switching device as it works to isolate or change the state of an electric circuit from one state to another. Different Types of Relays. Classification or the types of relays depend on the function for which they are used.

\section{F. ARDUINO UNO}

The Arduino Uno board is a microcontroller based on the ATmega328. It has 14 digital input/output pins in which 6 can be used as PWM outputs, a $16 \mathrm{MHz}$ ceramic resonator, an ICSP header, a USB connection, 6 analog inputs, a power jack and a reset button.

\section{MODULES}

The proposed system consists of four main modules. They are:

- RFID Detection

- $\quad$ Face Recognition

- $\quad$ iris Recognition

- Intruders detection

\section{A. RFID Detection}

Radio-Frequency IDentification (RFID) uses electromagnetic fields to automatically identify and track tags attached to objects. The tags contain electronically-stored information. Passive tags collect energy from a nearby RFID reader's interrogating radio waves. It reads the RFID card and pass it to arduino and then the arduino will pass to pc.

Input - scans the RFID from the authenticated user's card

Output - recognize the account and sends signal for further security check-ups if not recognised scan the card again.

\section{B. Face Recognition}

The next step of the process requires, every authorized member to successfully complete a face recognition in order to open that vault room and one half of the designated locker. At a time, only 2 of the 4 authorized members may access the vault. A maximum of 1attempts are accepted, on failure of which, the alarm will go off along with a alert notification being sent to the nearby police station, a bank official and the account holder.

Algorithms used here are fisher face, PCA, KNN.

Input: The trained data and the captured image.

Output: Recognized face

\section{Iris recognition}

Iris recognition is an automated method. In order to open the remaining half of the locker, we place the iris scanner across the vault room. Any of the authorized 2 members, can complete this procedure to open the vault. A maximum of 2 attempts are accepted, on failure of which, the alarm will go off along with an alert notification being sent to the nearby police station, a bank official and the account holder.

Algorithms used here are Hough transform and canny edge detection

Input: The trained data and the captured edges of the iris

Output: The matched iris

\section{Intruders detection}

IR Infrared Obstacle Avoidance Sensor Module has a pair of infrared transmitting and receiving tubes. When the transmitted light waves are reflected back, the reflected IR waves will be received by the receiver tube. The onboard comparator circuitry does the processing and the green indicator LED comes to life.The onboard preset helps to fine tune the range of operation, effective distance range is $2 \mathrm{~cm}$ to $80 \mathrm{~cm}$.

Input: Motion signal detected by the proximity sensor

Output: Alarm when motion detected 


\author{
Vol. 8, Issue 2, February 2019
}

\title{
V. CONCLUSION
}

\section{A. Conclusion}

In this project, we proposed to overcome the shortcomings (as in security) of the current vault systems provided in private banks. We intend to automate the manual security mechanism present at the moment so as to improve security levels and strength of the mechanism. We implemented three algorithms that is PCA, KNN, Hough Transform. PCA \& KNN is used to identify and recognize person face as well as Hough Transform for detecting person's iris. Also we include, IOT device to receive and send signals via serial Port. By using those technique we got $69 \%$ of accuracy to protect bank system with security.

\section{B. Future Enhancement}

Including laser technology in the proposed system will be an additional feature to enhance the security of the system. Chloroform can also be a backup for avoiding intruders.

\section{REFERENCES}

[1]. B.Sudarshan Akshaya R.k Mohan Reddy B,Srinivasa,Ramya L.K,'High Protection Voice Identification based Bank Locker Security System with Live Image",International Journal for Research in Applied Science and Engineering Technology(IJRASET),Volume 6,Issue 6,June 2018

[2]. Ms.D.Binu,M.Arun Athithyan,G.K.Felins,A.Mohammed Anish ,D.Sathish Kumar,"Secure Bank Locker System with Biometrics”,National Conference on Networks,Intelligence and Computing Sysrems,March 2017

[3]. ShivKumar Mishra,Kaila Bansree,RAHUL Lone,Sagar Kothawade,"Bank Locker Security System”,International Journal of Research in Science and Engineering,Volume 3,Issue 2,March-April 2017

[4]. Mr. Lokesh M. Giripunje1, Suchita Sudke2, Pradnya Wadkar3, Krishna Ambure,’IOT Based Smart Bank Locker Security System”, International Journal for Research in Applied Science \& Engineering Technology (IJRASET), Volume 5 Issue XI November 2017

[5]. Ripan Kumar Ray, Muhammad Afsar Uddin, Muhammad Afsar Uddin, "GSM Based Bank Vault Security System", Article in International Journal of Computer Science and Information Security (IJCSIS), Vol. 14, No. 2, February 2016

[6]. Shailika Sharma,,Mirtunjay Kumar,Satyajeet Kumar,"Bank Locker Security System based On RFID and GSM Technology”,Journal of Engineering Technologies and Innovative Research(JETIR),Volume 3,Issue 5,May 2016

[7]. Abhijeet s. Kale,Aniket V. Deshmukh,Mangesh V .Benodkar,Prasad K.Nage,Suyog P.Fukate, "Design of Banking Security System Using Mems And RFID Technology", The International Journal Of Engineering And Science (IJES), 26 February 2015

[8]. Abhilasha A Sayar, Dr.Sunil N Pawar,Security Bank Locker System Using Embedded System,International Journal Of Advanced Research in Electronics and Communication Engineering(IJARECE)Volume 4,Issue 8,August 2015

[9]. Sayemul Islam,Md.Saiduzzaman,"Design of a Bank Vault Security System with password thermal and physical interrupt", International Journal of Scientific \& Engineering Research, Volume 4, Issue 8, August 2013

[10]. Amit Verma, A Multi Layer Bank Security System, International Conference on Green Computing, Communication and Conservation of Energy, December 2013 